\title{
DISCUTINDO AS TEORIAS SOBRE CURRÍCULO ESCOLAR
}

\author{
DISCUSSING SCHOOL CURRICULUM THEORIES
}

\author{
Patrícia Aparecida Bioto-Cavalcanti \\ Doutora pela PUC-SP, São Paulo - SP - Brasil. \\ patriciacavalcanti@uni9.pro.br \\ Fabio Cavalcanti \\ Mestre pela USP-SP, São Paulo - SP - Brasil. \\ fabbiocant@gmail.com
}

\begin{abstract}
Resumo: Esse texto tem como objeto de estudo a discussão do currículo escolar. Seu objetivo é reapresentar ideias correntes de acordo com algumas questões norteadoras constitutivas das discussões curriculares. Para tanto, trará a tona a argumentação de autores que, historicamente, dentro do campo, tem construído teorias sobre o currículo. A exposição de tais ideias pautar-se-á pela busca de respostas a algumas questões, como por exemplo: como o currículo deve ser composto, elaborado; qual sua finalidade social, e como o materializar nas escolas, nos saberes e fazeres de professores e alunos. A metodologia de pesquisa aqui utilizada é a bibliográfica. As fontes consultadas foram livros, capítulos de livros e artigos de periódicos. Como conclusão podese apontar que o currículo se constitui como um dispositivo escolar de tal potência no universo científico, dada suas possibilidades de interpretação, discussão teórica e interlocução com tantas áreas do conhecimento escolar que precisa ser sempre discutido.
\end{abstract}

Palavras-chave: Currículo. Dispositivos escolares. Políticas educacionais. Professor. Aluno.

Abstract: This text has as object of study the discussion of the school curriculum. Its objective is to present current ideas according to some guiding questions constitutive of curricular discussions. To this end, it will bring up the argument of authors who, historically, within the field, have built theories about the curriculum. The exposition of such ideas will be guided by the search for answers to some questions, such as: how the curriculum should be composed, elaborated; what is its social purpose, and how to materialize it in schools, in the knowledge and practices of teachers and students. The research methodology used here is bibliographic. The sources consulted were books, book chapters and journal articles. In conclusion, it can be pointed out that the curriculum is constituted as a school device of such power in the scientific universe, given its possibilities of interpretation, theoretical discussion and dialogue with so many areas of school knowledge that always needs to be discussed.

Keywords: Curriculum. School devices. Educational policies. Teacher. Student.

\section{Para citar - ABNT NBR 6023:2018}

BIOTO-CAVALCANTI, Patrícia Aparecida; CAVALCANTI, Fabio. Discutindo as teorias sobre currículo escolar. Cadernos de Pós-graduação, São Paulo, v. 19, n. 1, p. 3-13, jan./jun. 2020. Disponível em: https://doi.org/10.5585/cpg.v19n1.14591. 
Introdução

Aponta-se como uma das origens etimológicas da palavra currículo o termo latino currere, que significa curso, correr, percurso. Tais palavras remetem tanto a uma ação, o correr, o percorrer, quanto aos substantivos, percurso e caminho. Assim, o currículo, em si, é tanto um substantivo quanto o deflagrador de uma ação. Indica tanto o objeto, a coisa, quanto o que decorre dela. Há sempre no currículo uma ideia de ação impregnada. O percurso é algo feito para ser percorrido. O curso é sempre o curso de algo, começa de um ponto, é composto por muitos outros, e se completa em um ponto final, em um término - que pode ser o começo de outro curso, de outro caminho.

No vocabulário educacional, David Hamilton (1992) dá notícia que o termo surgiu entre fins do XVI e início do XVII em documentos da Universidade de Leiden e Glasgow e no Oxford English Dictionary. Neste período vários fenômenos sociais estão ocorrendo em paralelo: o surgimento dos Estados nacionais modernos, as reformas religiosas, a imprensa, a chegada de europeus a continentes distantes, progressos científicos etc. Está em processo também a configuração de uma forma diferente de escola: a escola moderna. Fundamental para este texto é apontar que para esta escola um fator de tornou predominante, fundamental, desde sua proposição, qual seja, a ordem, a disciplina, o rigor, o organizar, o separar, o estabelecer começos, meios e fins, para o trabalho dos alunos, para o trabalho dos professores, para a relação entre ambos e para o que intermediava esta relação e a qualificava, o conhecimento a ser ensinado e a ser aprendido.

Séries, níveis e graus foram estabelecidos para a separação das turmas de acordo com as idades e os saberes dos quais os alunos demonstravam que possuíam. Para cada turma um saber específico a ser trabalhado, atividades próprias e livros adequados, anteriormente escolhidos. Uma vez indicado o que fazer com determinados alunos em determinada série, uma atividade consensual e processual se estabelecia. Seguia-se o padrão. Para a próxima série, o mesmo e assim sucessivamente até a terminalidade estabelecida. Um ponto de partida, um caminho a ser percorrido, um objetivo a ser atingido. E o dispositivo pedagógico que congregou, expressou e potencializou tal processo educacional foi, e é, o currículo (Cf. Hamilton, 1992)

Atualizando a discussão sobre o currículo, pode-se recorrer a Moreira (2007: 18), que indica que o currículo compreende "[...] as experiencias escolares que se desdobram em torno do conhecimento, em meio a relações sociais, e que contribuem para a construção das identidades de nossos/as estudantes." Mas pode ainda estar ligada, segundo o autor (idem), aos conteúdos, aos planos pedagógicos, aos objetivos do processo de ensino e a avalição.

Sobre o currículo tem-se produzido, desde o início do século passado, teorias, que discutem muitos aspectos ligados ao currículo. Entre eles pode-se citar as seguintes indagações presentes nas teorias curriculares, indagações feitas sobre o currículo e para o currículo: (1) como deve ser 
composto, elaborado; (2) qual sua finalidade social; (3) como o materializar nas escolas, nos saberes e fazeres de professores e alunos; (4) qual conhecimento deve compor o percurso educacional dos alunos, como os definir; (5) quem é o aluno que fará o percurso, como ele é, como ele deve ser ao percorrer o caminho e quando o completar; (6) que teorias de aprendizagem considerar para estabelecer os currículos e as atividades pedagógicas e de aprendizagem; (7) como deve ser o professor para cada currículo; (8) qual a influência social na determinação dos currículos; (9) qual o peso dos currículos nos projetos de escola e de sociedade; (10) qual a metodologia de ensino adequada; (11) qual a forma de avaliação adequada; (12) como o comunicar a comunidade escolar e a sociedade ampla e, (13) quem o deve elaborar.

Diversos autores de diferentes escolas filosóficas, sociológicas, políticas e educacionais, tem dado suas respostas a estes questionamentos. Eles compuseram, segundo Silva (2017) teorias do currículo. Tais teorias têm sido classificadas em três: tradicional, crítica e pós-crítica. A exceção da primeira, que foi denominada pelos teóricos que olharam para ela a posteriori da elaboração dos textos fundantes, as demais, a teoria crítica e a teoria pós-crítica do currículo, se autodenominaram, afirmando uma identidade teórica e um objetivo.

\section{Por que teoria do currículo?}

Cabe questionar com Silva (2017) o significado da palavra teoria. Seria teoria o exercício intelectual de olhar um objeto de existência precedente ao exercício e então dissecá-lo em busca de sua essência, de suas características e de suas funções? Se isso for teoria, então o determinante na relação é a coisa a ser conhecida, pois a teoria sobre ela não existiria sem ela. Neste ponto, a teoria é o reflexo, a leitura feita e a elaboração teórica sobre o objeto que se apresenta aos sentidos para ser conhecido.

Mas nesta relação pode haver outro determinante, a teoria, de acordo com as abordagens pós-estruturalistas. Para esta corrente, a teoria cria o objeto sobre o qual constrói a elaboração. "A 'teoria' não se limitaria, pois, a descobrir, a descrever, a explicar a realidade: a teoria estaria irremediavelmente implicada na sua produção. Ao descrever um 'objeto', a teoria, de certo modo, inventa-o. O objeto que a teoria supostamente descreve é, efetivamente, um produto de sua criação” (Silva, 2017, p. 11).

Para as chamadas "teorias do currículo", caberia, na verdade, mas apropriadamente, continua o autor, o termo discurso, pois o discurso produz seu próprio objeto (p. 12). No caso do currículo, o debruçar-se inicial sobre ele pode ser localizado nos Estados Unidos na década de vinte do século passado (p. 13). Aqueles que se ocuparam do objeto currículo, então, não o fizeram apenas para conceituá-lo, caracterizá-lo, mas para propor uma ideia de currículo, um modelo de 
currículo, um modo de fazer currículo e fazê-lo funcionar segundo aquilo que defendiam ser as necessidades sociais e educacionais da época. Eles propuseram um currículo, eles produziram uma “[...] noção particular de currículo" (p. 12).

\section{Teoria tradicional do currículo}

Para este movimento foi dado o nome de teoria tradicional do currículo. Tradicional pois segundo os teóricos críticos do currículo, o que Bobbit e Tyler pretendiam fazer com suas obras sobre currículo era manter a ordem social vigente. O discurso dos autores era de acomodação e de prospecção de modos de alimentar um modo de vida, um modo de organização da vida social correspondente aos interesses da classe dominante da sociedade. As mudanças que propuseram vinham no sentido de aperfeiçoar a educação para cumprir os fins postos pelo processo de industrialização e modernização social. No livro de Franklin Bobbit, The Curriculum, de 1918, e no de Ralph Tyler, Princípios básicos de currículo e ensino, de 1949, as perguntas feitas são predominantemente de como organizar as aprendizagens, o ensino e os conhecimentos escolares de modo a que os objetivos educacionais propostos sejam alcançados.

Quando Bobbit escreveu sua obra, a sociedade americana passava se via diante de alguns desafios. Entre eles pode-se citar a necessidade de capacitar mão de obra para trabalhar nas indústrias, mão de obra que era composta tanto por americanos quanto por imigrantes, e a necessidade de preparar cidadãos que se adequassem a um estilo de vida urbano e capitalista. As escolas deveriam se nortear por valores de ordem, progresso, desejo de sucesso individual, de conquista de bens materiais por meio do trabalho assalariado, de disciplina cívica, de produção de um consenso sobre a necessidade de cada cidadão participar ativamente na produção de uma nação líder e de potencialização das capacidades individuais.

Para tanto a definição dos currículos escolares é tarefa precípua. Os currículos das escolas as definem e definem os homens que ali serão ali formados. Há que se pensar no que ensinar, para quem ensinar e no como ensinar. É uma lógica pragmatista, taylorista. Cada qual cumpre sua função do modo que foi instruído a fazer para que aquilo que foi determinado que deveria ser feito seja alcançado com perfeição, economia e rapidez.

Para definir os currículos, escreve Tyler (1986), há que se definir em primeiro lugar que objetivos educacionais a escola deve procurar alcançar. Desde agora deve-se ter em vista que cada discurso elaborado é feito com uma finalidade. Ele fala a um público, defende ideias, se opõe a outras, fala com alguns, para alguns e contra outros. Todo e qualquer discurso é na verdade uma arma, um instrumento, uma ferramenta, um utensílio. Tem um fim. É preparado para isso. Para atingir seu fim deve ser o mais adequado, mais bem feito, afiado e afinado possível. Deve usar o 
que há de melhor em conhecimento disponível. Deve conhecer os problemas do campo em que vai se inserir, seus consensos e seus conflitos e deve produzir um consenso sobre o tema que trata partindo da consideração de todos esses elementos. E assim fez Tyler.

Para compor os objetivos educacionais defendeu que deveria se partir do conhecimento disponível sobre o aluno e sobre os fins da escola. Para tanto chamou para si as contribuições da Psicologia, disciplina em ascensão no período. Considerou também várias escolas filosóficas que discutiam o homem em si, e optou para a que ressaltava aquele homem operante, desejoso do bem de todos, encaixado, útil. E isto tudo numa lógica produtiva, em que o ser humano é mais uma peça. A escola o deve convencer disto e o preparar para tal. A organização do currículo escolar tem papel fundamental neste processo.

\begin{abstract}
Deve-se visar a um número pequeno de objetivos educacionais e não grande, uma vez que se demora em alcançá-los; em outras palavras, é necessário tempo para modificar padrões de comportamento de seres humanos. Um programa educacional não é eficaz quando se empreende tanta coisa que muito pouco é realizada. É essencial, por conseguinte, selecionar o número de objetivos que podem ser realmente atingidos num grau significativo dentro do tempo disponível, e que esses sejam objetivos realmente importantes. Mais ainda: o conjunto de objetivos deve ter alto grau de coerência, a fim de que o estudante não seja lançado em confusão de padrões contraditórios de comportamento humano (Tyler, 1986, p. 30).
\end{abstract}

Tyler está a ensinar aos envolvidos com a elaboração de currículos para sistemas de ensino e escolas como fazer currículos definidos em função de objetivos claros e exequíveis. Obedecendo para tanto a uma lógica de eficiência e economia de recursos e tempo. Desta forma o aluno será educado em uma escola tão produtiva quanto a fábrica em que irá trabalhar e/ou a função que irá executar. A escola não deve se perder em seus objetivos, deve ser clara, direta, exata. Afinal, há muitos padrões contraditórios de comportamento e neles as escolas não devem perder tempo e esforços. Não há lugar para a contradição, para o conflito, para a dúvida, para o erro nas escolas, nas indústrias e na sociedade. As escolas devem produzir o burguês aperfeiçoado em seu mais alto grau, que é o homem americano.

E a este ideário produtivista, reprodutivista e tecnicista da sociedade, das escolas e dos currículos, o grupo dos teóricos críticos da sociedade e do currículo se opuseram. A partir de meados da década de sessenta do século passado pensadores europeus, norte-americanos e brasileiros começaram a questionar o status quo. Se dedicaram a elaborar um questionamento radical aos arranjos sociais e educacionais vigentes e às forças sociais e de conhecimento dominantes. Ao contrário das ideias tradicionais sobre o currículo procuram desenvolver conceitos sobre o que o currículo faz e não sobre como fazer currículo (CF. Silva, 2017, p. 30). 


\section{Teoria crítica do currículo}

Como representantes da teoria crítica do currículo pode-se apontar alguns autores e obras. Entre elas a de Louis Althusser, Aparelhos ideológicos do estado, de 1970 e Michael Apple, Ideologia e Currículo, de 1979.

Althusser afirma que a sobrevivência do capitalismo reside na manutenção dos valores capitalistas e que tal se dá por meio do funcionamento de aparelhos, de instituições arranjos sociais encarregados de incorporar, defender e propagar tal ideário. Entre estas instituições estão a família, a igreja e as escolas. Estas são aparelhos ideológicos pois sua força reside nas estratégias de convencimento e de formação de um espírito acrítico e passivo frente aos ditames capitalistas que se colocam como os únicos, viáveis, válidos e que mantem a vida e a ordem social, protegendo a humanidade do caos, da guerra, da fome da morte. Mesmo que para isto os promova, em última instância, o que, obviamente, não está dito pelos aparelhos ideológicos do estado.

Se a empreitada de coerção e formação dos aparelhos ideológicos não surte o efeito esperado entram em cena os aparelhos de estado, a polícia, os tribunais, a cadeia, que operam pela força física e não pela força ideológica, o que não exclui estes aparelhos de deter e operar com um arcabouço ideológico. O que também não exclui de escolas, famílias e igrejas o uso da força física, da coerção física.

As escolas, segundo Althusser, são aparelhos privilegiados e de extremo interesse para o estado. A escola detém para si todas as crianças, ricas e pobres, dos seis aos 20 anos de idade, de 4 a 6 horas por dia, de 200 a 250 dias por ano. Por estes pontos apenas se pode depreender como sua ação é extensiva e intensiva.

Procurando desvelar as relações entre a escola, a sociedade e currículo, Michael Apple (2006) afirma que tais relações se dão basicamente num universo simbólico. É possível ver na forma de organização das escolas, nas posturas e falas dos professores, no que é ensinado aos alunos, tanto em termos de conhecimentos escolares quanto em termos de normas de comportamento, a presença de valores de uma sociedade baseada na concorrência, na desigualdade e a construção de superioridades e inferioridades.

Acho que estamos começando a enxergar mais claramente coisas que antes eram obscuras. Á medida que aprendemos a entender a maneira pela qual a educação atua no setor econômico de uma sociedade, reproduzindo aspectos importantes de sua desigualdade, também aprendemos a desvendar uma segunda esfera em que a escolarização opera. Não há apenas a propriedade econômica, há também da propriedade simbólica, o capital cultural, que as escolas preservam e distribuem. Assim, podemos agora começar a entender mais perfeitamente como as instituições de preservação e distribuição cultural, como as escolas, criam e recriam formas de consciência que permitem a manutenção do controle social sem a necessidade de os grupos dominantes terem de apelar a mecanismos de dominação (p. 37). 
Operando em todas as frentes da escola, embrenhando-se em suas práticas, nos saberes ensinados e aprendidos, nas leis e códigos de ensino, nos regimes de seriação e certificação, a ideologia capitalista entra em um processo de saturação como meio de se difundir e perpetuar. Apple chama este processo de hegemonia.

\begin{abstract}
A ideia fundamental engastada nesta citação é a de como a hegemonia atua para 'saturar' nossa própria consciência, de maneira que o mundo educacional, econômico e social que vemos e com o qual interagimos, bem como as interpretações do senso comum que a ele atribuímos, se torna o mundo tout court, o único mundo. Assim, a hegemonia se refere não à acumulação de significados que estão em um nível abstrato em algum lugar da "parte superior de nossos cérebros'. Ao contrário, refere-se a um conjunto organizado de significados e práticas, ao sistema central, eficaz e dominante de significados, valores e ações que são vividos (Apple, 2006, p. 39).
\end{abstract}

A este "conjunto organizado de significados e práticas" que são vividos na escola pode-se também dar o nome de experiência escolares. As experiências escolares encarnam-se num currículo, que é tanto a organização destas experiências, materializada em documentos e práticas assumidas como autorizadas e desejadas tendo em vista este currículo formal, quanto o que está subentendido mas que é praticado de uma maneira igualmente legitimada e autorizada, pois de acordo com os valores e normas que compõem o currículo formal, que é o currículo oculto.

Currículo formal e currículo oculto são desenhados e exercitados considerando relações de poder. Estas se expressam já na seleção do que deve ser ensinado e aprendido. Qual conhecimento é considerado válido para ser ensinado nas escolas? O conhecimento científico. E os outros conhecimentos? O mitológico, o espiritual? Estes são menores, não são universais, não passaram pelo crivo da ciência. Logo, não devem chegar às escolas. Nas escolas só o melhor, mais útil e válido para as crianças. Nisto já está sendo ensinado valores de submissão, de não necessidade de posicionamentos, de exercício da livre vontade e da escolha. Não é preciso escolher, debater, alguém preocupado com o bem dos alunos, da escola e do mundo já fez isto. Ele sabe o que faz. Estudou para isto. Leu vários teóricos. Sabe o que faz e o que fala. Para que preciso me preocupar em questionar e escolher? Eu não sei. Há apenas um conhecimento válido. Há apenas uma alternativa correta. O restante está errado. É melhor eu aderir ao que está certo, caso contrário serei a alternativa errada e alternativas erradas não são consideradas e aceitas.

Nas escolas o erro não é considerado como algo construtivo, mas como algo a ser superado. Nas provas de múltipla escolha as alternativas incorretas desaparecem depois da correção. Elas perdem o direito de existir.

Assim como os alunos que erram, que não sabem. Eles perdem o direito de existir, de estar na escola. E se lá permanecem vão engrossar as estatísticas do fracasso, fracasso escolar e fracasso social. Um fracasso encoberto, velado, mas que uma hora aparece. 
É uma escola que busca a eficiência e a eficácia. O conhecimento mais adequado para formar aquele homem ideal. O professor cujas práticas dão mais resultado, cujas aulas não dão problemas, que controla os alunos. Os alunos mais comportados, dedicados, estudiosos, preocupados com o futuro, que participam das atividades escolares. Úteis, obedientes, produtivos, que tiram boas notas e aprendem. Que aproveitam a escola. Afinal, vão para a escola para quê? Para aprender!

Esta é a hegemonia. Esta é a saturação. Esta é uma expressão ideológica que se quer afirmar como a única validade e útil. Esta é a desigualdade de expressando na escola e em seu currículo.

Mas as conclusões que podem ser tiradas das ideias de Apple vão além da afirmação da hegemonia. Apple expressa também um pensamento contra hegemônico.

\begin{abstract}
Não posso aceitar uma sociedade na qual uma em cada cinco crianças nasce na pobreza, condição que piora a cada dia. Também não posso aceitar como legítima uma definição de educação na qual nossa tarefa é preparar os alunos para 'funcionarem' facilmente nos 'negócios' de uma tal sociedade. Um país não é uma empresa. A escola não é parte dessa empresa, e sua função não é buscar produzir incessantemente o 'capital humano' necessário para administrá-la. Realmente acabamos com nosso conceito de bem comum se pensarmos na situação dramática da educação nestes termos. É algo que diminui o papel dos professores e cria um processo educacional que permanece desconectado das vidas de muitas crianças (Apple, 2006, p. 28).
\end{abstract}

Continua o autor: “[...] não posso conceber que possamos entender 'como as relações de dominação, sejam elas materiais, sejam simbólicas, poderiam operar sem implicar ou ativar alguma resistência” (idem, p. 25). Resistência que existe nas escolas, que pode existir, se não existe. "A educação é tanto a 'causa' quanto o 'efeito'. A escola não é um espelho passivo, mas uma força ativa, que pode também servir para legitimar as formas econômicas e sociais e as ideologias tão intimamente conectadas a ela. É justamente esta ação que precisa ser revelada” (p. 76).

\title{
Teoria pós-crítica do currículo
}

Central para as discussões e formulações teóricas sobre o currículo é também a cultura. Cultura entendida em sua visão antropológica, como o conjunto de valores e práticas compartilhadas pelos grupos sociais. A ênfase está no que é compartilhado. O valor da cultura está em relação com o grupo a que pertence, com o significado que tem para o grupo. Não há um valor em si, mas um valor atribuído. O que faz sentido é o significado, não o significante, como nas teorias tradicionais sobre cultura.

Nestas assumia-se como cultura o grupo de objetos e práticas de um grupo social específico, a classe dominante privilegiada, possuidora da cultura geral, culta, instruída, civilizada. Esta classe possuía a cultura em si. A cultura a ser buscada e mirada por todas as classes sociais. Possuir este 
capital cultural fazia parte do processo de distinção entre as classes. O capital cultural era expressão direta do capital econômico. E este capital cultural, ao qual não tinha acesso as crianças das classes desfavorecidas era o que as marcava na escola, assinalando seu fracasso. O que se privilegiava nas escolas era o capital cultural de um determinado grupo. Quem não o possuía não possuía os códigos que permitiam ler os códigos da escola, se manter nela e ter sucesso (Bourdieu, 2013).

Uma vez superado este conceito de cultura, assume-se a escola como o lugar em que devem estar presentes as culturas, o conjunto de práticas e valores que tem significado para os diversos grupos sociais presentes nas escolas. E a preocupação com o lugar destes grupos, de seus valores, de suas culturas, com sua expressão e inserção nos currículos escolares faz parte do que constrói a teoria pós-crítica do currículo.

Não se pode afirmar que haja nas teorias pós-críticas um único discurso, um único articulador dos discursos, um único receptor. Tais teorias abrangem uma diversidade de temas antes calados nas discussões e nas escolas. Estabelecem diálogos com várias questões: de gênero, de etnia, de sexualidades, de identidade, de possibilidades contra hegemônicas etc.

Quanto a questão da identidade, o que se busca nas discussões curriculares propositivas, é um espaço para que antes de serem definidos os processos constituintes de identidades, haja espaço para outras discussões. Pode-se apontar as seguintes possibilidades de questionamentos: o que é ter identidade? Por que deve se ter uma identidade? É possível ter apenas uma? É válido? Qual sua função? Em que ter uma identidade se relaciona com a existência humana e sua expressão? O que é mais importante no processo de construção identitária? Há um começo e um término para ele? Há uma identidade válida ao gênero humano? Há várias identidades: individual, profissional, familiar, social etc? Qual a relação de minha identidade com a do outro? Há interferências?

Coloca-se aqui uma questão bastante importante para os pós-críticos: o outro. Historicamente o outro tem se constituído como o diferente, o ameaçador, o que deve ser neutralizado e/ou eliminado, quando não modifica para se tornar semelhante. Este é um processo visível em guerras, invasões, processos de aculturação, de formação de uma identidade heroica. O outro deve ser afastado ou dominado. Mas os pós-críticos sugerem um tratamento diverso. O outro é o que permite a expressão da alteridade da personalidade e encarna as potências existentes no mundo que eu posso acessar diretamente ou indiretamente. Ele se constitui como uma ponte, como uma possibilidade. Com ele posso olhar para dentro e para fora. E neste movimento descobrir o que me pertence e o que não me pertence em termos existenciais. Com o outro me construo.

Destas considerações nascem as propostas de currículos marcadamente multiculturais, que consideram os outros que até então foram calados nos currículos, nas escolas e na sociedade. E o 
desvelamento deste processo de transformação, de inclusão, se constitui um processo de construção de possibilidades contra hegemônicas (Cf. Moreira e Candau, 2007, p. 34-35).

\section{Considerações finais}

Para finalizar o texto vale a pena retomar a ideia que o currículo pode ser entendido como uma série de experiências escolares, que congrega conteúdos, modos de ensinar e aprender, identidades, formas de avaliação, modos de socialização, que indica a relação da escola com a comunidade, da escola com o saber, com a política, com o modo de produção da vida material e com os objetivos do processo educacional, para alunos, professores e para a sociedade como um todo. Procurou-se neste texto tecer considerações sobre tais elementos de acordo com as diversas teorias curriculares.

Muito ainda há para ser dito sobre estes tantos outros pontos que compõem os discursos, as teorias curriculares. Muito sobre o que já foi escrito sobre o tema, muito do que ainda não foi dito e escrito. Muito do que se ouve nas escolas, suas indagações e suas sugestões. Ainda há vozes pouco ouvidas nos discursos curriculares. Ainda há lugares que lidam diretamente com o currículo, que o tem na base de sua atividade, de sua constituição, que o discute, que se apropria dele, que o desconstrói, que o reconceitualiza, que apresenta ou não resistências.

O currículo configura-se como um dispositivo pedagógico de excelência. Por dispositivo podemos entender com Ane Marie Chartier (2002) um objeto, uma prática, uma ideia de força tal que concentra e engendra posturas, significados, possibilidades e propostas. É construído coletivamente, ao longo do tempo, em relação a contextos sociais e escolares específicos. Adquire a voz daqueles que o construíram, sendo assim um objeto privilegiado de leitura da sociedade e de sua educação. Por este mesmo motivo, é campo de disputa de interesses e projetos. Se há uma palavra que pode resumir currículo, seria movimento. O que difere em muito da ideia de grade curricular, muito presente nas propostas e documentos curriculares de um passado não muito distante.

Afirmar a dinamicidade e a heterogeneidade do currículo é afirmar o mesmo quanto a escola e quanto aos estatutos e perfis daqueles que lá estão a se configurar, notadamente, professores e alunos.

Nenhuma teoria curricular foi construída desprezando tais elementos, muito pelo contrário. Partiram das ideias, dos estudos e dos objetivos acerca destes sujeitos para se formarem, para dialogarem e para se projetarem num espaço e num tempo social.

As teorias sobre o currículo quebram a afamada dicotomia entre teoria e prática. Elas foram e são construídas tendo em vista os contextos em que se inseriam e se inserem. Leem, analisam 
propõe. Se põe em ação. Envolvem os sujeitos das politicas de estado e os sujeitos de dentro da escola.

E é a dinâmica social que lhe impinge transformações. Nas teorias curriculares. E tais transformações estendem-se às práticas pedagógicas de professores e à aprendizagem dos alunos.

Um dispositivo de tal potência no universo científico, dada suas possibilidades de interpretação, discussão teórica e interlocução com tantas áreas do conhecimento escolar precisa ser sempre discutido.

Muito ainda há para ser dito sobre estes e tantos outros pontos que compõem os discursos, as teorias curriculares. Sobre o que já foi escrito sobre o tema, sobre o que ainda não foi dito e escrito. Sobre o que se ouve nas escolas, suas indagações e suas sugestões. Ainda há vozes pouco ouvidas nos discursos curriculares. Ainda há lugares que lidam diretamente com o currículo, que o tem na base de sua atividade, de sua constituição, que o discute, que se apropria dele, que o desconstrói, que o reconceitualiza, que apresenta ou não resistências e que não são locais de construção do currículo. Tais lugares e sujeitos precisam ser ouvidos e mais do que isso, precisam falar por si, pois são os aqueles que encarnam currículos propostos, documentados, formais e ocultos.

\section{Referências}

ALTHUSSER, Louis. Aparelhos ideológicos do Estado. Lisboa. Editorial Presença, Martins Fontes, s/d. Disponível em https://politica210.files.wordpress.com/2014/11/althusser-louis-ideologia-eaparelhos-ideolc3b3gicos-do-estado.pdf. Acesso em 17 de abril de 2018.

APPLE, Michael. Ideologia e Currículo. Trad. Vinicius Figueira. $3^{\text {a }}$ ed., Porto alegre; Artmed, 2006.

BOURDIEU. Pierre. A escola conservadora: as desigualdades frente à escola e à cultura. In: NOGUEIRA, Maria Alice, CATANI, Afrânio. Escritos de Educação. 14ª ed., Petrópolis,, RJ: Vozes, 2013, p. 43-72.

CHARTIER, Anne-Marie. Um dispositivo sem autor: cadernos e fichários na escola primária. Revista Brasileira de História da Educação. Campinas, 2002, nº 3, p. 9-26.

HAMILTON, David. Sobre as origens dos termos classe e curriculum. Teoria e educação, $\mathrm{n}^{\circ} 6$, 1992, p. 33-51.

MOREIRA, Antonio Flavio; CANDAU, Vera Maria. Currículo, Conhecimento e Cultura. Indagaçoes sobre currículo. Brasília, MEC/SEB, 2007, p. 17-42

SILVA, Tomaz Tadeu. Documentos de identidade: Uma Introdução às Teorias de Currículo. $3^{\circ}$ Edição. Editora Autêntica. 2017.

TYLER, Ralph. Princípios básicos de currículo e ensino. Trad. Leonel Vallandro. $9^{\mathrm{a}}$ ed. Porto Alegre, Rio de Janeiro: Globo, 1986. 